\title{
Extraction, Purification, Optimization, and Application of Galactomannan-Based Edible Coating Formulations for Guava Using Response Surface Methodology
}

\author{
Ammara Ainee $\mathbb{D}^{1},{ }^{1}$ Sarfraz Hussain, ${ }^{1}$ Muhammad Nadeem, ${ }^{1}$ Asaad R. Al-Hilphy, \\ and Azhari Siddeeg $\mathbb{1}^{3}$ \\ ${ }^{1}$ Institute of Food Science and Nutrition (IFSN), University of Sargodha, Sargodha, Pakistan \\ ${ }^{2}$ Department of Food Science, College of Agriculture, University of Basrah, Basrah, Iraq \\ ${ }^{3}$ Department of Food Engineering and Technology, Faculty of Engineering and Technology, University of Gezira, \\ Wad Medani, Sudan \\ Correspondence should be addressed to Ammara Ainee; ammara.ainee@uos.edu.pk and Azhari Siddeeg; \\ azhari_siddeeg@uofg.edu.sd
}

Received 22 September 2021; Revised 31 October 2021; Accepted 16 December 2021; Published 10 January 2022

Academic Editor: Ali Noman

Copyright $\odot 2022$ Ammara Ainee et al. This is an open access article distributed under the Creative Commons Attribution License, which permits unrestricted use, distribution, and reproduction in any medium, provided the original work is properly cited.

\begin{abstract}
Galactomannan from fenugreek and guar seeds were extracted, purified, and used in edible coatings, optimized via response surface methodology. The results showed that the emulsifying capacity and stability of fenugreek galactomannan (FG) and guar galactomannan (GG) increased with increase in the concentration of galactomannan up to $0.5-1 \%$. The average optimized values of FG and GG in edible coatings were predicted to be $1.71 \%$ and $2.11 \%$ for weight loss, $0.72 \%$ and $2.14 \%$ for firmness, $1.02 \%$ and $1.44 \%$ for TSS, $0.83 \%$ and $1.36 \%$ for $\mathrm{pH}, 1.03 \%$ and $1.44 \%$ for acidity, respectively. Significant decrease in weight loss and maximum retention of firmness was observed in coated guava. The TSS increased up to a certain storage period in all treatments and decreased as the storage period progressed, whereas $\mathrm{pH}$ exhibited an increasing trend while a significant decrease in acidity was observed. The findings revealed that the shelf life of guava could considerably be improved by incorporating $1.24 \%$ galactomannan from GG and $1.01 \%$ from FG in the edible coating.
\end{abstract}

\section{Introduction}

Guava (Psidium guajava L.) is a well-renowned fruit in Pakistan [1]. Guava quickly softens and thus has poor shelf stability that is susceptible to shipping and storage damage [2-4]. The guava's shelf life varies with the ambient temperature from three to five days [5]. Between harvest and consumption, significant losses are rendered in the quality and quantity of fruits and vegetables [6]. Food packaging innovations can help alleviate changing market demands such as consumer choice for safe and high-quality food items, and the decrease in environmental adverse effects of food packaging [7]. The need for a replacement for synthetic packaging with bio-based polymers is important.

Edible coatings can significantly increase shelf life and enhance food quality by the reduction in weight and moisture loss, creating barrier properties against oil, gas, aroma, and flavor. The preservation of mechanical, rheological attributes, food color, and appearance of food are also improved. It is an environmentally friendly invention $[6,8]$. Edible coatings generate a protective environment around the fruits and vegetables [9].

Galactomannans, water-soluble heterogeneous polysaccharides found in many leguminous seeds and mainly consists of mannose and galactose. They differ from each other by the mannose/galactose ratio. Fenugreek, guar gum, locust bean gum, and alfalfa are the most common sources of galactomannans [10]. It finds applications in different sectors (pharmaceutical, textile, cosmetics, biomedical, and food) due to its versatile characteristics and nontoxic effect. In the food industry, galactomannans are extensively used in film/coating formulation, dietary, 
powdered and baby foods, soups, seasoning, sauces, meat, bakery, and dairy products [11].

Extraction and utilization of polysaccharides from plant and animal sources have gained significant attention in recent times because of their stability, biodegradability, and ecologically friendly. Guar gum is a natural polysaccharide [12]. Guar gum is extracted from the endosperm of guar seeds belongs to the family Leguminosae and is commonly known as guar, guaran, or cluster bean [13]. The chief suppliers of guar throughout the world are Pakistan and India, where $80 \%$ of the total guar is produced [14]. Guar gum is expensive and forms a viscous gel in cold water, so it is extensively used in different food products and industries as a stabilizer as well as an emulsifying and thickening agent [15].

Fenugreek (Trigonella foenum-graecum) is a popular spice consumed globally and commonly known as "Methi" [16]. It is widely grown in Pakistan, Turkey, China, Egypt, India, and the Mediterranean [17]. The seeds of fenugreek are rich in gum, fiber, alkaloids, flavonoids, saponins, and volatile compounds [18]. The plant seeds are a good source of polysaccharides [19]. In the past, fenugreek use in the manufacture of food has been increased by its emulsifying, thickening, and stabilizing properties in many food products [20].

The ripening process continues in guava even after detaching from trees and respire at a higher rate due to climacteric in nature. Due to short shelf life, marketing and subsequent storage of guava are difficult. Therefore, some treatments that can extend shelf life and conserve the quality of guava fruits are required (Anjum et al.) [21]. The study of postharvest physiology is of immense importance. The shelf life of fresh fruit is short at room temperature without any pre or posttreatment during storage. Reduction in losses and waste of fresh guava is essential for the fact that this fruit provides vital nutrients. Keeping in view the abovementioned facts, current research work was carried out to improve the quality characteristics and extend the shelf life of local variety (Gola) of guava during the storage period by optimization of polysaccharides levels in edible coatings through the response surface methodology (RSM). Thus optimum galactomannan-based coating formulation was the main objective of the study and to study the effect of coating on quality attributes as well as shelf stability of guava.

\section{Materials and Methods}

2.1. Raw Materials. Fenugreek and guar seeds were purchased from the local market of Sargodha, Punjab, Pakistan. Freshly picked guava cv gola, for coating purposes, was purchased from guava orchard at Sargodha district, Punjab province (Figure 1). The ripe fruits were selected along with the stem, uniform size, color, free of any physical damage and fungal infestation, further followed by manual sorting and grading in the laboratory. Olive oil (extra light) and glycerin were purchased from the market at Sargodha. Chemicals including ethanol, isopropanol, and $\mathrm{NaCl}$ were purchased from Sigma-Aldrich, Germany available in the local market.
2.2. Extraction and Purification of Polysaccharide from Guar and Fenugreek Seeds. The seeds of guar and fenugreek were soaked separately in water overnight at room temperature. The polysaccharide extraction and purification were carried out according to the method described by [19]. Cleaned whole seeds were crushed and immersed for $24 \mathrm{hrs}$ at $50^{\circ} \mathrm{C}$ in a $5 \%$ salt solution having $3 \mathrm{pH}$ adjusted by acetic acid. The polysaccharides were extracted separately by muslin cloth. Crude gums were purified by the addition of IPA spirit (a blend of $10 \%$ isopropanol and $90 \%$ ethanol) in a ratio of $3: 1$ by volume with continuous stirring followed by centrifugation at $6000 \mathrm{rpm}$ for $7 \mathrm{~min}$. The white precipitate obtained from both gums was filtered by muslin cloth. The pomace of seeds was again immersed in a $5 \%$ salt solution of $3 \mathrm{pH}$ until the maximum gum was extracted following the purification procedure. The purified polysaccharides were dried in an oven at $50^{\circ} \mathrm{C}$ for $24 \mathrm{hrs}$. The purified dried polysaccharide was weighed and stored in airtight jars at a cool dry place for further utilization and analysis (supplementary Figures 1-6).

2.2.1. Emulsifying Properties. The emulsifying capacity (EC) and stability of the polysaccharides were determined according to [19] with some minor modifications. Suspension $(60 \mathrm{ml})$ of each gum was prepared with an increase in the galactomannan concentration $(0.5,0.75,1.0 \% \mathrm{w} / \mathrm{v})$, at the same commercial olive oil level $(6 \mathrm{ml})$ homogenized at $10,000 \mathrm{rpm}$ for $1 \mathrm{~min}$. The suspensions were then centrifuged at $1300 \mathrm{rpm}$ for $5 \mathrm{~min}$. EC was calculated as

$$
\text { emulsion capacity }(\%)=\frac{\text { emulsion volume }}{\text { total volume }} \times 100 \text {. }
$$

Emulsion stability (ES) against high temperatures were determined in the emulsions that were heated in a water bath at $80^{\circ} \mathrm{C}$ for $30 \mathrm{~min}$ and centrifuged at $1300 \mathrm{rpm}$ for $5 \mathrm{~min}$. The ES was calculated as

$$
\text { emulsion stability }(\%)=\frac{\text { final emulsion volume }}{\text { initial volume }} \times 100 \text {. }
$$

2.3. Edible Coating Formulation. The coatings were prepared following the protocol of Vishwasrao and Ananthanarayan [2] with minor modifications. Purified polysaccharides extracted from fenugreek and guar seeds were used in the formulations of coating as a source of thickening, gelling, and stabilizing agent, glycerol as a plasticizer, olive oil as hydrophobic phase, and distilled water to make the edible coating. Measured amounts of guar galactomannan (GG) and fenugreek galactomannan (FG) powder were dissolved in $100 \mathrm{ml}$ distilled water according to the treatment plan created by the central composite design and stirred by hot plate magnetic stirrers to form a gel, and then emulsifying agent (glycerol) was added. After the addition of oil, the mixture was homogenized for $5 \mathrm{~min}$ to get physically and chemically stable, inert, and nongreasy emulsion (Table 1). Emulsions prepared were cooled at room temperature and were kept in clean, dried, and airtight glass bottles for further application for one week. 




Figure 1: The geographic location of procurement of guava fruits.

TABLE 1: Edible coating formulations from fenugreek galactomannan and guar galactomannan through central composite design.

\begin{tabular}{|c|c|c|c|c|c|}
\hline Treatments & Fenugreek galactomannan $(\mathrm{g} / 100 \mathrm{ml})$ & Guar galactomannan $(\mathrm{g} / 100 \mathrm{ml})$ & Olive oil $(\mathrm{ml} / 100 \mathrm{ml})$ & $\begin{array}{c}\text { Glycerin } \\
(\mathrm{ml} / 100 \mathrm{ml})\end{array}$ & $\begin{array}{c}\text { Distilled water } \\
(\mathrm{ml} / 100 \mathrm{ml})\end{array}$ \\
\hline $\mathrm{EC}_{0}$ & & & Control & & \\
\hline $\mathrm{EC}_{1}$ & 1.00 & 1.5 & 5 & 0.3 & 92.2 \\
\hline $\mathrm{EC}_{2}$ & 1.00 & 0.80 & 5 & 0.3 & 92.9 \\
\hline $\mathrm{EC}_{3}$ & 0.30 & 1.50 & 5 & 0.3 & 92.9 \\
\hline $\mathrm{EC}_{4}$ & 1.00 & 1.50 & 5 & 0.3 & 92.2 \\
\hline $\mathrm{EC}_{5}$ & 1.00 & 2.20 & 5 & 0.3 & 91.5 \\
\hline $\mathrm{EC}_{6}$ & 1.71 & 1.50 & 5 & 0.3 & 91.49 \\
\hline $\mathrm{EC}_{7}$ & 1.00 & 1.50 & 5 & 0.3 & 92.2 \\
\hline $\mathrm{EC}_{8}$ & 0.50 & 1.00 & 5 & 0.3 & 91.2 \\
\hline $\mathrm{EC}_{9}$ & 1.00 & 1.50 & 5 & 0.3 & 92.2 \\
\hline $\mathrm{EC}_{10}$ & 1.00 & 1.50 & 5 & 0.3 & 92.2 \\
\hline $\mathrm{EC}_{11}$ & 1.50 & 1.00 & 5 & 0.3 & 92.2 \\
\hline $\mathrm{EC}_{12}$ & 0.50 & 2.00 & 5 & 0.3 & 92.5 \\
\hline $\mathrm{EC}_{13}$ & 1.00 & 1.50 & 5 & 0.3 & 92.5 \\
\hline $\mathrm{EC}_{14}$ & 1.5 & 2.00 & 5 & 0.3 & 91.2 \\
\hline
\end{tabular}

2.4. Preparation of Fruit Samples. Selected guavas were washed, rinsed, dried, and dipped in chlorinated water (chlorine level up to $150 \mathrm{ppm}$ ). After that guavas were divided into ten lots, each carrying an equal number (15 No) of fruits, and were coated by emulsion, prepared according to the treatment formulation except $\mathrm{EC}_{0}$ (control), via the dipping method. Each fruit was dipped for one minute, twisted, and placed in baskets, then allowed to dry for 20 minutes at room temperature. Before dipping guava in the solution, the mixture was homogenized to get a uniformly dispersed emulsion. The coated guavas were placed in baskets at the storage temperature of $24 \pm 5^{\circ} \mathrm{C}$ and stored for about 20 days.

2.5. Physico-Chemical Analysis. The weight of each coated and uncoated fruit was recorded by the electronic weighing balance, on $1^{\text {st }}$ day of the experiment and after every 5 days interval for 20 days and the weight loss percentage were calculated. The fruit firmness was measured by using a penetrometer (model GY-2, Walfront, USA) and expressed as $\mathrm{kg} / \mathrm{cm}^{2}$. A refractometer (RHB-32 ATC model, China) was used for the determination of total soluble solids (TSS) of the guava fruit juice and expressed as Brix. acidity (acetic acid) was determined by titrating the juice against $0.1 \mathrm{M}$ sodium hydroxide solution and six drops of phenolphthalein until the color changed to faint pink color. The volume of $\mathrm{NaOH}$ used was noted to get the value of acid (in grams per $100 \mathrm{~mL}$ ). A digital calibrated $\mathrm{pH}$ meter ( $\mathrm{PH}-8414$ model) was used to measure the $\mathrm{pH}$ of juice according to the standard method [22]. The experiment was performed in triplicate; three fruits were taken each time after every five days.

2.6. Statistical Analysis. Multiple regressions to fit secondorder polynomial equation through response surface methodology was applied to estimate the responses of fenugreek and guar gum used as independent variables during storage. Central composite design was used to optimize the levels of independent variables using Minitab 16 statistical software. Response surface graphs were generated to see the effects of independent variables on dependent variables. The data were analyzed by Nadeem et al. [23]. 


\section{Results and Discussion}

3.1. Emulsifying Properties. Due to high surface energy on the contact surface of oil and water molecules, thermodynamic emulsions are unstable and can result in the complete separation of two immiscible layers by coalescence; therefore, the stability of emulsions was examined. Emulsions prepared with high concentrations of galactomannan have been found to be more stable and have higher emulsion capacity [19].

Emulsions containing various concentrations of galactomannan $(0.5,0.75,1.0 \% \mathrm{w} / \mathrm{v})$ showed pronounced emulsifying property which increased with increasing galactomannan concentration up to $1.0 \%$ but the FG showed slightly lower than GG. The emulsion stability (ES) and emulsion capacity (EC) of guar galactomannan and fenugreek galactomannan are shown in Table 2. GG provided an excellent emulsion stabilization effect during two weeks of storage period at $25^{\circ} \mathrm{C}$ as compared to FG. Moreover, emulsions with $0.5 \%$ of GG and FG could even maintain the emulsification stability up to $94 \%$ and up to $97 \%$ over two weeks, respectively.

As the concentration of polysaccharides increases, the globules become more strongly enclosed in polymeric conformation. Higher polymer concentrations provide good viscosity to the aqueous phase, which further prevents the mobility of the globules and slows their amalgamation. The emulsifying properties of the hydrocolloids are either due to their interface behavior or their viscosity modifying properties that further inhibit the contact of the globules which also allows more time for the polymer to be absorbed in the interface [24].

3.2. Physico-Chemical Properties. Polysaccharides from guar galactomannan and fenugreek galactomannan were used in different levels to increase the shelf-life of guava. The effect of fenugreek and guar galactomannan on the physicochemical properties of guava fruit during storage (at $0,5,10,15$, and 20 days) was assessed. The RSM was applied to estimate the responses of fenugreek and guar galactomannans used as independent variables during storage.

3.3. Weight Loss. Weight loss in guava during ripening is due to both transpiration and respiration. Weight loss results in textural changes and surface shrinkage that adversely affects the shelf life of climacteric fruits and vegetables. The models were developed for weight loss of guava fruit as affected by independent variables during 20 days storage. The results depicted in Table 3 and Figure 2 revealed the significant effect of fenugreek galactomannan and guar galactomannan on weight loss in guava fruits during 20 days. The linear terms of FG and GG have a statistically significant $(p<0.05)$ effect for weight loss during the storage period. The FG ${ }^{2}$ and $\mathrm{GG}^{2}$ quadratic terms are found significant at $5,10,15$, and 20 days storage intervals. The coefficients of determination $\left(R^{2}\right)$ were studied as above $90 \%$ at most of the storage intervals, therefore it could be assured that models are well fitted and the coefficients of polynomial equations were calculated by the equations given at the top of each graph (Figure 1). Optimized average values of fenugreek and guar galactomannan in the edible coating were found to be $1.70 \%$ and $2.10 \%$, respectively. A decrease in weight loss was observed in edible-coated guava fruits during storage intervals. These results were found parallel to the findings of previously reported studies $[25,26]$. Edible coatings reduced the respiration rates, water loss, and oxidation reaction rates by making a semipermeable barrier against oxygen $\left(\mathrm{O}_{2}\right)$, carbon dioxide $\left(\mathrm{CO}_{2}\right)$, moisture, and solute movement. The cumulative loss in weight increased gradually in all the treatments by advancement in storage duration. Coatings act as a barrier to desiccation and lead to maintained fresh weight of fruits (Khaliq et al.) [27]. Increased concentrations of polysaccharides allowed the formation of a thick layer around the fruit surface which retains firmness by reducing the loss of moisture and gas permeability. In this work, physiological weight loss was probably lower in coated fruits due to inhibited desiccation.

3.4. Firmness. Firmness is associated with water content and metabolic changes that occur in fruits and it is an important parameter that affects consumer acceptability [28]. The models were developed for the firmness of guava fruit as affected by fenugreek galactomannan and guar galactomannan during 20 days storage (Figure 3 ). The statistical analysis by applying the analysis of variance technique to the full regression of model (Table 4) shows a significant effect of FG and guar galactomannan. However, linear and quadratic terms of FG and GG are observed to positively change the firmness of fruits at $5,10,15$, and $20^{\text {th }}$ day of storage intervals, whereas at $1^{\text {st }}$ day of storage have no effect. When the interaction of these two terms (FG * GG) was studied, it was found negative for all storage intervals. The coefficients of determination $\left(R^{2}\right)$ were more than $85 \%$, indicating wellfitted response models. The data showed that FG and guar galactomannan contributed toward firmness in guava fruit at 5 to 20 days storage intervals (Figure 2). For good firmness, optimized average values of fenugreek galactomannan and guar galactomannan in the edible coating were predicted to be $0.72 \%$ and $2.14 \%$, respectively. The results showed that the optimized formulation was effective in maintaining the firmness of the guava fruit. The abovegiven results of firmness were similar to previous study results [29]. Another research reported a few variations in texture changes during the storage period [30]. Moreover, the edible coating is helpful in maintaining firmness [31].

3.5. TSS. The regression coefficients of variables in models showed that fenugreek galactomannan and guar galactomannan did not contribute toward change in TSS in guava fruits at the start of storage, but after that contributed significantly from $5^{\text {th }}$ to 20 days storage intervals. The effect of linear terms of FG and GG are statistically significant $(p<0.05)$ for TSS at all days of storage intervals except the start of the study (Figure 4 and supplementary Table 1 ). The $X^{2}$ quadratic terms are found significant at $5,10,15$, and 20 days storage intervals, whereas, the quadratic terms for $\mathrm{FG}^{2}$ 
TABLE 2: Emulsion capacity and stability of fenugreek galactomannan and guar galactomannan.

\begin{tabular}{lccr}
\hline Galactomannan & Concentration $(\mathrm{g})(\% \mathrm{w} / \mathrm{v})$ & Emulsion capacity (\%) & Emulsion stability (\%) \\
\hline \multirow{3}{*}{ Fenugreek } & 1.0 & $98.23 \pm 0.15$ & $97.17 \pm 0.11$ \\
& 0.75 & $96.73 \pm 0.15$ & $95.87 \pm 0.15$ \\
\hline \multirow{3}{*}{ Guar } & 0.5 & $94.8 \pm 0.1$ & $94.57 \pm 0.35$ \\
& 1.0 & $98.83 \pm 0.15$ & $99.06 \pm 0.06$ \\
& 0.75 & $97.13 \pm 0.06$ & $98.83 \pm 0.15$ \\
\hline
\end{tabular}

TABLe 3: Analysis of variance (sum of the square) for response surface model of weight loss of guava fruits during storage.

\begin{tabular}{|c|c|c|c|c|c|}
\hline \multirow{2}{*}{ SOV } & \multirow{2}{*}{ Df } & \multicolumn{4}{|c|}{ Days } \\
\hline & & 5 & 10 & 15 & 20 \\
\hline Model & 5 & $22.8021^{*}$ & $8.4648^{*}$ & $22.5618^{*}$ & $13.5515^{*}$ \\
\hline Linear & 2 & $1.6024^{*}$ & $0.1901^{*}$ & $0.0951^{*}$ & $1.1588^{*}$ \\
\hline FG & 1 & $1.1915^{*}$ & $0.1321^{*}$ & $0.0882^{*}$ & $1.1581^{*}$ \\
\hline GG & 1 & $0.4109^{*}$ & $0.0580^{*}$ & $0.0069^{*}$ & $0.0006^{*}$ \\
\hline Square & 2 & $21.1907^{*}$ & $8.2195^{*}$ & $19.5255^{*}$ & $8.5903^{*}$ \\
\hline $\mathrm{FG} * \mathrm{FG}$ & 1 & $20.5353^{*}$ & $0.3314^{*}$ & $10.9630^{*}$ & $1.1501^{*}$ \\
\hline $\mathrm{GG} * \mathrm{GG}$ & 1 & $12.3077^{*}$ & $6.4152^{*}$ & $19.0467^{*}$ & $7.7648^{*}$ \\
\hline 2-way interaction & 1 & $0.0090^{\mathrm{ns}}$ & $0.0552^{\text {ns }}$ & $2.9412^{\text {ns }}$ & $3.8025^{\mathrm{ns}}$ \\
\hline $\mathrm{FG} * \mathrm{GG}$ & 1 & $0.0090^{\mathrm{ns}}$ & $0.0552^{\mathrm{ns}}$ & $2.9412^{\mathrm{ns}}$ & $3.8025^{\mathrm{ns}}$ \\
\hline Error & 3 & 0.6967 & 3.8930 & 11.6652 & 6.3300 \\
\hline Total & 8 & 23.4988 & 12.3578 & 34.2270 & 19.8815 \\
\hline$R$-square (\%) & & 94.04 & 88.50 & 95.92 & 88.16 \\
\hline
\end{tabular}

If $p>0.05,{ }^{\text {NS }}$ non-significant ( $\left.p>0.05\right) ; p>0.05,{ }^{*}$ significant; and $p>0.01,{ }^{* *}$ highly significant fenugreek galactomannan (FG), guar galactomannan (GG).



0

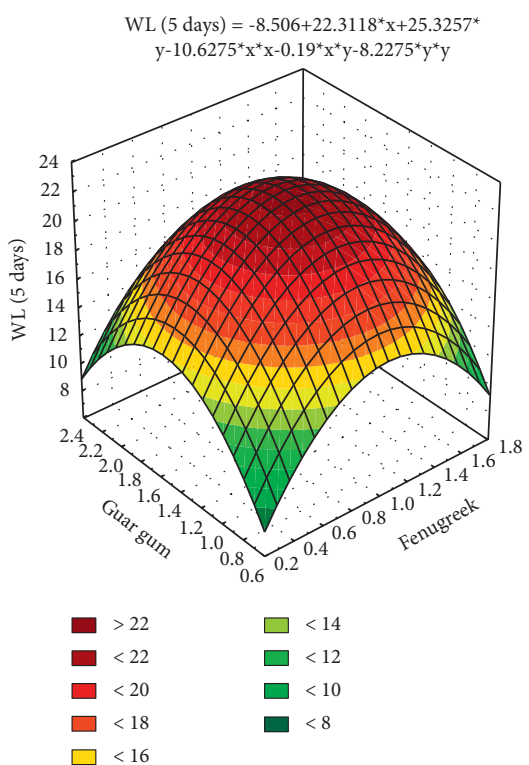

(b)

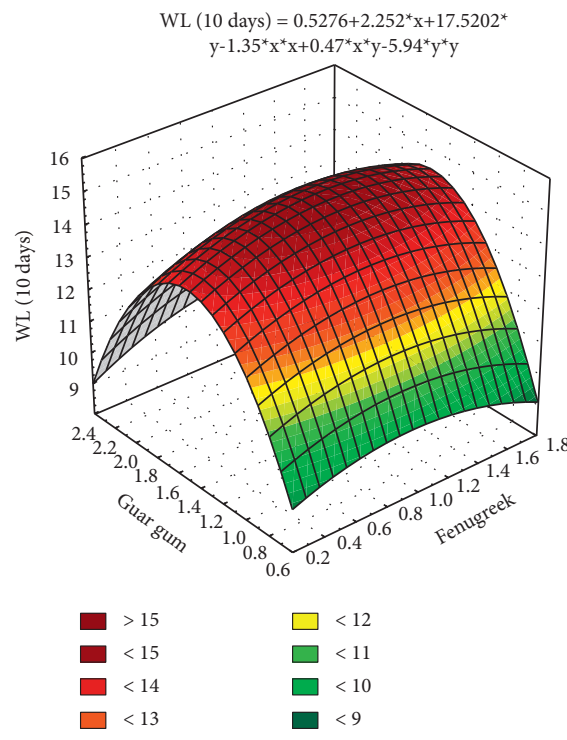

(c)

Figure 2: Continued. 


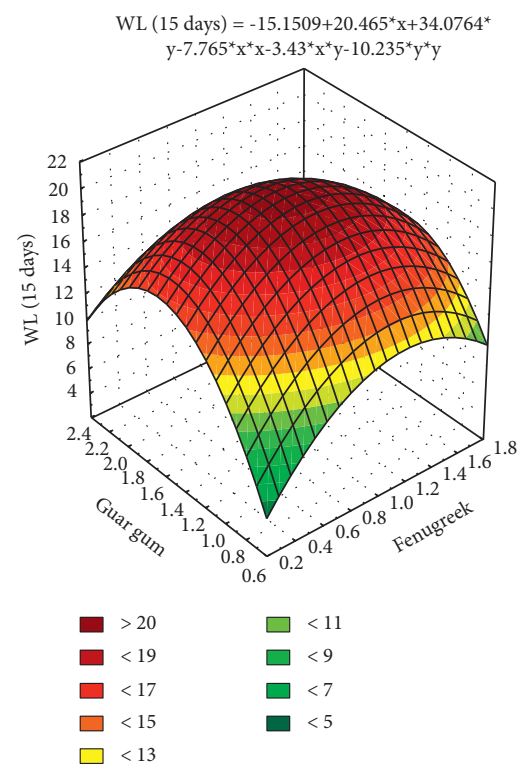

(d)

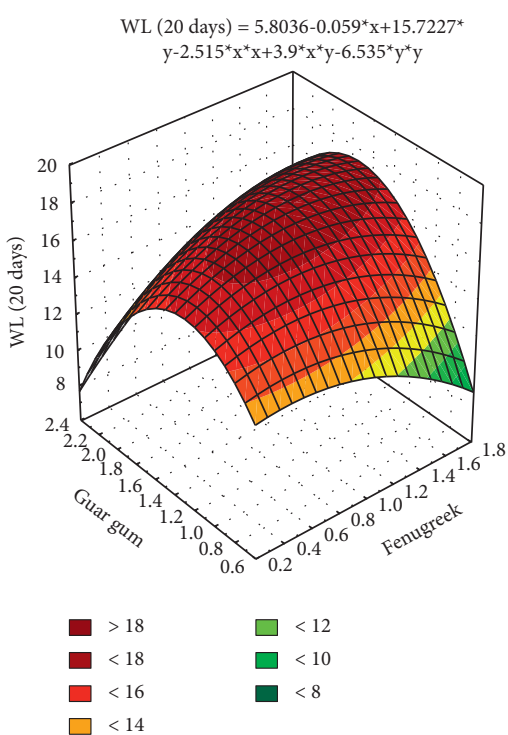

(e)

FIgURE 2: Response surface plot showing the impact of guar galactomannan and fenugreek galactomannan on weight loss of guava fruit during storage. (a) WL (0 days) $=0+0 * x+0 * y+0 * x * x+0 * x * y+0 * y * y$. (b) WL (5 days) $=-8.506+22.3118 * x+25.3257 * y-$ $10.6275 * x * x^{-} 0.19 * x * y-8.2275 * y * y$. (c) WL $(10$ days $)=0.5276+2.252 * x+17.5202 * y^{-} 1.35 * x * x+0.47 * x * y^{-} 5.94 * y * y$. (d) WL $(15$ days $)=-15.1509+20.465 * x+34.0764 * y-7.765 * x * x-3.43 * x * y^{-} 10.235 * y * y$. (e) WL $(20$ days $)=5.8036-0.059 * x+$ $15.7227 * y^{-} 2.515 * x * x+3.9 * x * y^{-} 6.535 * y * y$.

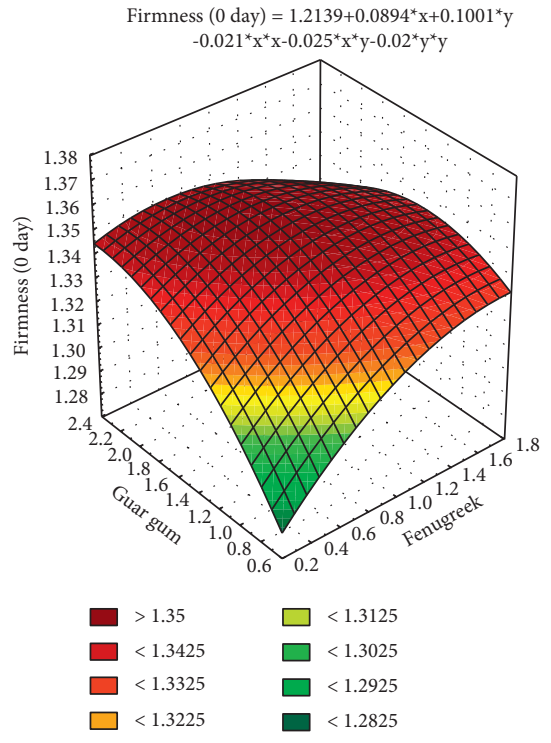

(a)

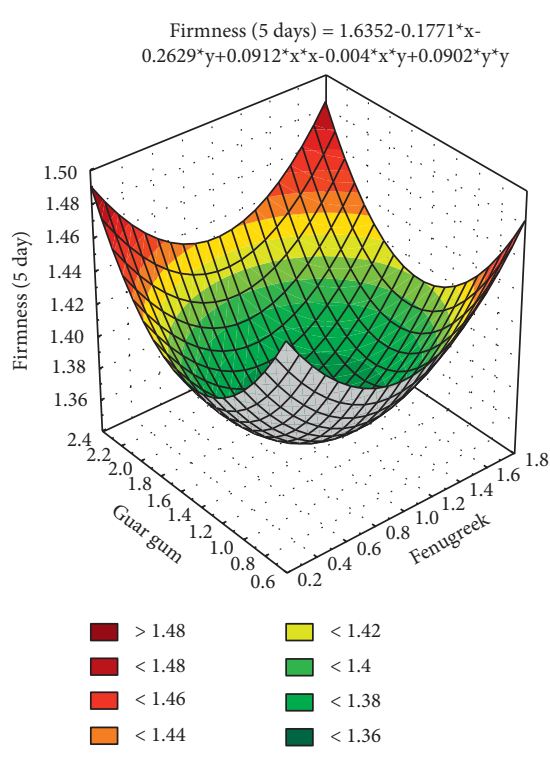

(b)

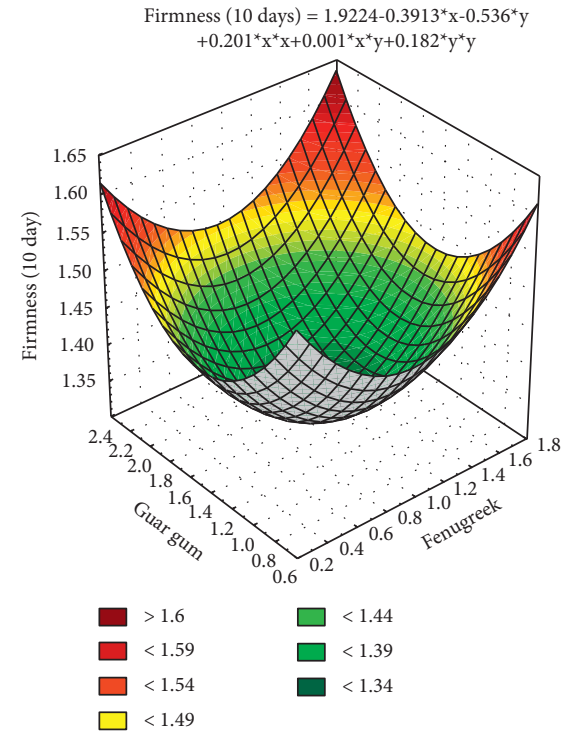

(c)

FIgURE 3: Continued. 


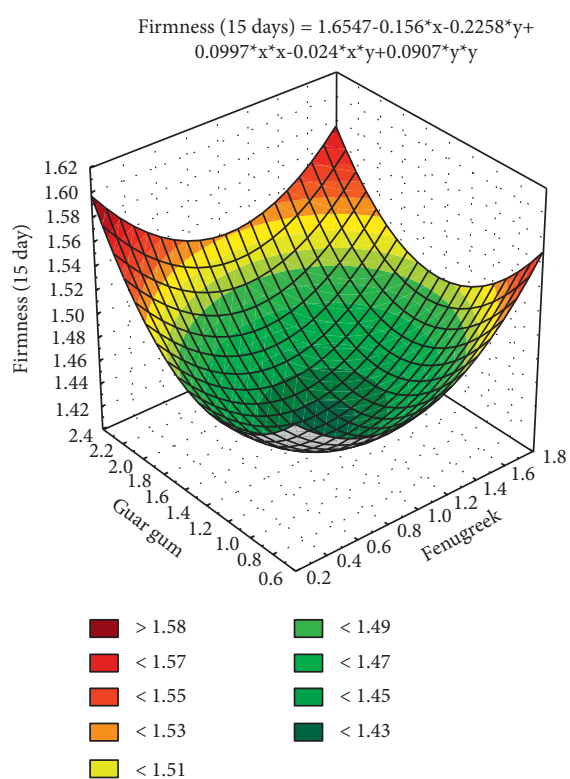

(d)

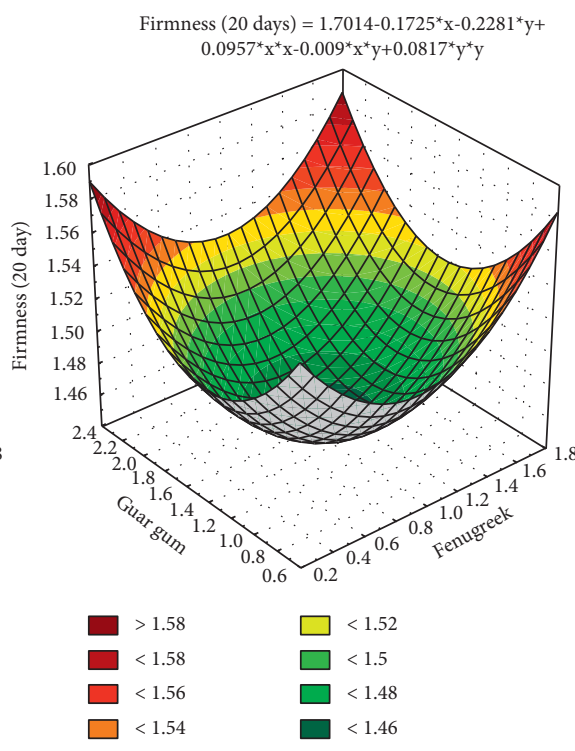

(e)

FIgURE 3: Response surface plot showing the impact of guar galactomannan and fenugreek galactomannan on the firmness of guava fruit during storage. (a) Firmness $(0$ days $)=1.2139+0.0894 * x+0.1001 * y-0.021 * x * x-0.025 * x * y-0.02 \times y * y$. (b) Firmness $(5$ days $)=$ $1.6352-0.1771 * x-0.2629 * y+0.0912 * x * x-0.004 * x * y+0.0902 * y * y$. (c) Firmness (10 days) $=1.9224-0.3913 * x-0.536 * y+0.201$ $* x * x+0.001 * x * y+0.182 * y * y$. (d) Firmness (15 days) $=1.6547-0.156 * x-0.2258 * y+0.0997 * x * x-0.024 * x * y+0.0907 * y * y$. (e) Firmness $(20$ days $)=1.7014-0.1725 * x-0.2281 * y+0.0957 * x * x-0.009 * x * y+0.0817 * y * y$.

TABle 4: Analysis of variance (sum of the square) for response surface model of fruit firmness during storage.

\begin{tabular}{|c|c|c|c|c|c|c|}
\hline \multicolumn{7}{|c|}{ Days } \\
\hline SOV & Df & 0 & 5 & 10 & 15 & 20 \\
\hline Model & 5 & $0.000902^{\mathrm{ns}}$ & $0.001865^{*}$ & $0.008777^{*}$ & $0.003303^{*}$ & $0.002014^{*}$ \\
\hline Linear & 2 & $0.000652^{\mathrm{ns}}$ & $0.000031^{*}$ & $0.000537^{\mathrm{ns}}$ & $0.001122^{*}$ & $0.000194^{\mathrm{ns}}$ \\
\hline Fenugreek (FG) & 1 & $0.000197^{\mathrm{ns}}$ & $0.000001^{*}$ & $0.000297^{\mathrm{ns}}$ & $0.000114^{*}$ & $0.000060^{\mathrm{ns}}$ \\
\hline Guar gum (GG) & 1 & $0.000455^{\mathrm{ns}}$ & $0.000030^{\mathrm{ns}}$ & $0.000240^{\mathrm{ns}}$ & $0.001009^{*}$ & $0.000134^{\mathrm{ns}}$ \\
\hline Square & 2 & $0.000094^{\mathrm{ns}}$ & $0.001830^{*}$ & $0.008240^{\mathrm{ns}}$ & $0.002036^{\mathrm{ns}}$ & $0.001799^{*}$ \\
\hline $\mathrm{FG} * \mathrm{FG}$ & 1 & $0.000080^{\mathrm{ns}}$ & $0.001514^{*}$ & $0.007346^{*}$ & $0.001809^{*}$ & $0.001667^{*}$ \\
\hline $\mathrm{GG} * \mathrm{GG}$ & 1 & $0.000073^{\mathrm{ns}}$ & $0.001481^{*}$ & $0.006023^{\mathrm{ns}}$ & $0.001497^{\mathrm{ns}}$ & $0.001215^{*}$ \\
\hline 2-way interaction & 1 & $0.000156^{\mathrm{ns}}$ & $0.000004^{\mathrm{ns}}$ & $0.000000^{\mathrm{ns}}$ & $0.000144^{*}$ & $0.000020^{\mathrm{ns}}$ \\
\hline $\mathrm{FG} * \mathrm{GG}$ & 1 & $0.000156^{\mathrm{ns}}$ & $0.000004^{\mathrm{ns}}$ & $0.000000^{\text {ns }}$ & $0.000144^{*}$ & $0.000020^{\mathrm{ns}}$ \\
\hline Error & 3 & 0.002181 & 0.000239 & 0.002070 & 0.000497 & 0.001094 \\
\hline Total & 8 & 0.003083 & 0.002104 & 0.010847 & 0.003800 & 0.003108 \\
\hline$R$-square (\%) & & 29.26 & 88.64 & 90.91 & 96.92 & 94.79 \\
\hline
\end{tabular}

If $p>0.05,{ }^{\mathrm{NS}}$ non-significant $(p>0.05) ; p<0.05,{ }^{*}$ significant; and $p<0.01,{ }^{* *}$ highly significant fenugreek galactomannan (FG), guar galactomannan (GG).

and $\mathrm{GG}^{2}$ are found significant at the $5^{\text {th }}$ and $10^{\text {th }}$ days. The interaction of two variables (XY) was nonsignificant at the start of the study and then significant effect on the TSS of guava fruits at various storage intervals. The coefficient of determination $\left(R^{2}\right)$ was low on the $1^{\text {st }}$ day and then was above $80 \%$ after the $5^{\text {th }}$ day, indicating that models are well fitted (Figure 3). The average optimized levels of fenugreek and guar galactomannan in the edible coating were found to be 1.02 and $1.44 \%$, respectively. The effect of edible coating on Brix of guava described that the total soluble solid increased up to a certain storage period in all the treatments and thereafter reduced as the storage period progressed. These results are consistent with previous findings [26]. The initial increase in TSS during storage was mainly due to the conversion of starch into soluble forms of sugars and the subsequent decrease in TSS was due to rapid utilization of reducing sugar and other organic metabolites [5].

3.6. $p H$. The regression coefficients of variables showed that FG and GG significantly affected the change in $\mathrm{pH}$ of guava fruits during storage. The effect of linear terms of fenugreek galactomannan and guar galactomannan are statistically significant $(p<0.05)$ for $\mathrm{pH}$ at all days of storage intervals (supplementary Figure 7 and supplementary Table 2). The $X^{2}$ quadratic terms $\left(\mathrm{FG}^{2}\right.$ and $\mathrm{GG}^{2}$ ) are found significant at 5,10 , 15 , and 20 days' storage intervals. The interaction of two variables $(\mathrm{FG} * \mathrm{GG})$ shows a significant effect on the $\mathrm{pH}$ of 


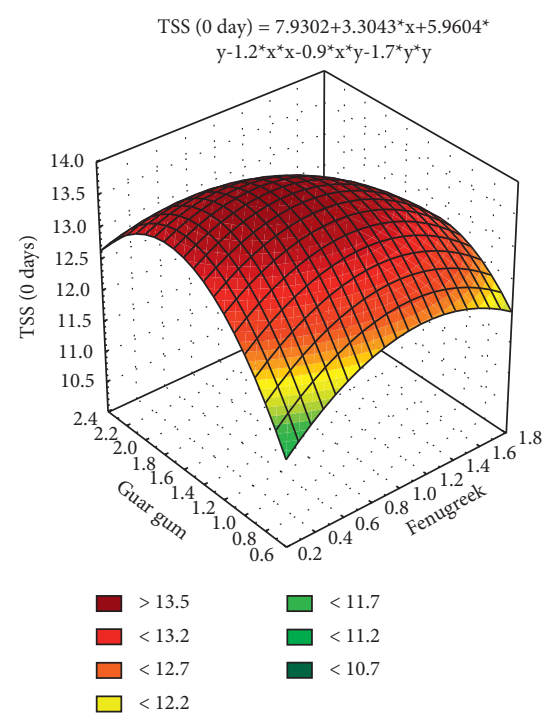

(a)

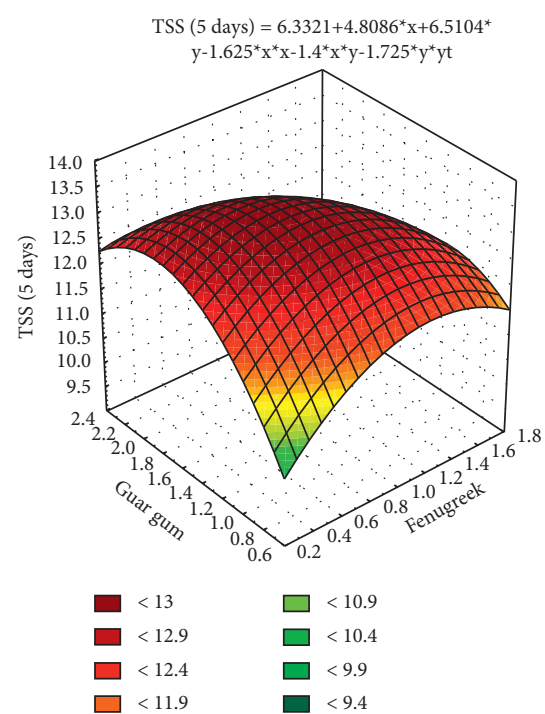

(b)



(c)



(d)

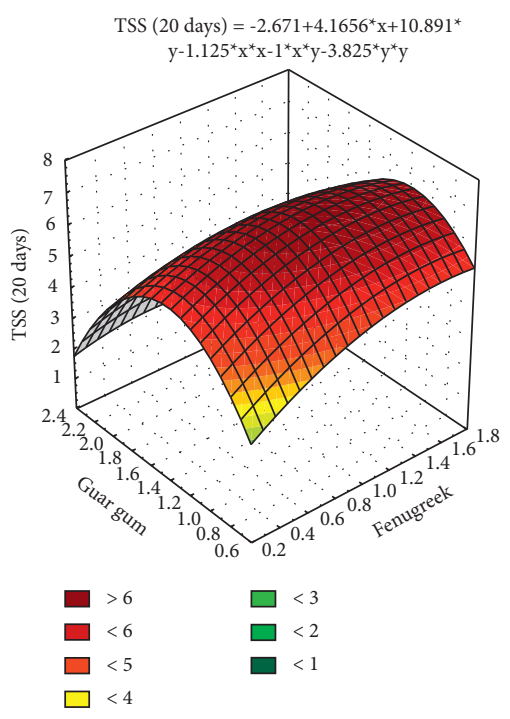

(e)

FIgURE 4: Response surface plot showing the impact of guar galactomannan and fenugreek galactomannan on TSS of guava fruit during storage. (a) TSS $(0$ days) $=7.9302+3.3043 * x+5.9604 * y-1.2 * x * x-0.9 * x * y-1.7 * \mathrm{y} * \mathrm{y}$. (b) TSS $(5$ days $)=6.3321+4.8086 * x+$ $6.5104 * y-1.625 * x * x-1.4 * x * y-1.725 * y * y$. (c) $\quad$ TSS $\quad(10 \quad$ days $)=1.2367+14.3253 * x+9.4129 * y-7.125 * x * x+0.4 * x * y-$ $3.625 * y * y . \quad$ (d) TSS $\quad(15$ days $)=10.479-0.0644 * x+11.2362 * y-4.675 * x * x+7.2 * x * y-6.575 * y * y$. (e) $\quad$ TSS $\quad(20 \quad$ days $)=$ $-2.671+4.1656 * x+10.891 * y-1.125 * x * x-1 * x * y-3.825 * y * y$.

guava fruits at all storage intervals. The coefficient of determination $\left(R^{2}\right)$ was $99.10 \%$ on the $1^{\text {st }}$ day, $96.78 \%$ on the $5^{\text {th }}$ day, $75.58 \%$ on the $10^{\text {th }}$ day, $88.48 \%$ on the $15^{\text {th }}$ day, and $82.13 \%$ on the $20^{\text {th }}$ day, indicating that models are well fitted (supplementary Figure 7).

A similar increasing trend in $\mathrm{pH}$ values of the galactomannan coated guavas throughout the storage period has been observed in the previously reported study [32]. Moreover, another study reported a minor raise in $\mathrm{pH}$ values after eight days of storage time [30]. That variation was occurred owing to the decrease in the amount of malic acid, because of the rise in respiration rate during cutting and peeling. The average optimized levels of fenugreek galactomannan and guar galactomannan in the edible coating were $0.83 \%$ and $1.36 \%$, respectively. The increased $\mathrm{pH}$ value was due to the development of organic acids through maturity or storage period [27].

3.7. Acidity. The regression coefficients of variables in models showed that the FG and GG did not contribute toward change in acidity in guava fruits at the start of storage but after that contributed significantly from $5^{\text {th }}$ to 20 days storage intervals. The effect of linear terms of fenugreek galactomannan and 
guar galactomannan are statistically significant $(p<0.05)$ for acidity at all days of storage intervals except the start of the study (supplementary Figure 8 and supplementary Table 3 ). The $X^{2}$ quadratic terms are found significant at $5,10,15$, and 20 days storage intervals, whereas the quadratic terms for $\mathrm{FG}^{2}$ and $\mathrm{GG}^{2}$ are found significant at $5^{\text {th }}$ and $10^{\text {th }}$ days. The interaction of two variables (XY) shows a nonsignificant effect at the start and a significant effect on the acidity of guava fruits after 5 days storage intervals. The coefficients of determination $\left(R^{2}\right)$ were well enough for well-fitted models (supplementary Figure 8). A significant decrease in acidity was observed at 5 , 10 , and 20 days of storage. The increase in $\mathrm{pH}$ and decrease in acidity in coated fruits was due to the reduction in respiration rate of fruits and consequently limit the over consumption of organic acids in respiration reactions [33]. The average optimized levels of fenugreek galactomannan and guar galactomannan in edible coating were $1.03 \%$ and $1.44 \%$, respectively. The reduction of organic acids leads to decline of $\mathrm{TA}$ that subsequently results in increased juice $\mathrm{pH}$ of guava fruits [34]. The influence of treatments and storage times was significant on titratable acidity (TA) of guava fruits. Overall, the TA was progressively decreased but the reduction was significantly higher in control than the treated guava fruits.

\section{Conclusion}

According to the present study, $1.24 \mathrm{~g}$ guar galactomannan and $1.01 \mathrm{~g}$ fenugreek galactomannan in edible coating appeared to be the optimum coating formulation for improving the postharvest quality of guava fruit. The response surface methodology was observed as an effective statistical tool to discriminate the interactive effects of independent variables. The FG and GGbased edible coating significantly reduced the weight loss and TSS. Moreover, the coated fruit was fresh, firmer, and low in TA during storage. Thus, the RSM could be effectively used to optimize edible coating formulations leading to the overall enhancement of the quality and shelf-life of guava fruit.

\section{Abbreviations}

$\mathrm{CO}_{2}$ : Carbon dioxide

CCD: Central composite design

EC: Emulsifying capacity

ES: Emulsion stability

FG: Fenugreek galactomannan

GG: Guar galactomannan

RSM: Response surface methodology

TSS: Total soluble solids

$\mathrm{O}_{2}$ : Oxygen.

\section{Data Availability}

The dataset supporting the conclusions of this article is included in the manuscript.

\section{Additional Points}

Practical Application. Galactomannan-based edible coating can be served as environmentally friendly packaging by replacing the use of chemicals and reducing packaging waste in the food industry.

\section{Conflicts of Interest}

The authors declare that they have no conflicts of interest.

\section{Acknowledgments}

The authors are grateful to the University of Sargodha for providing opportunity and support for this research work.

\section{Supplementary Materials}

Supplementary Figure 1: extraction and purification of guar galactomannan. Supplementary Figure 2: extraction and purification of fenugreek galactomannan. Supplementary Figure 3: XRD pattern of guar galactomannan. Supplementary Figure 4: XRD pattern of fenugreek galactomannan. Supplementary Figure 5: FTIR spectra of guar galactomannan. Supplementary Figure 6: FTIR spectra of fenugreek galactomannan. Supplementary Figure 7: response surface plot showing the impact of guar galactomannan and fenugreek galactomannan on $\mathrm{pH}$ of guava fruit during storage. Supplementary Figure 8: response surface plot showing the impact of guar galactomannan and fenugreek galactomannan on the acidity of guava fruit during storage. Supplementary Table 1: analysis of variance (sum of the square) for response surface model of fruit firmness during storage. Supplementary Table 2: analysis of variance (sum of the square) for response surface model of fruit TSS during storage. Supplementary Table 3: analysis of variance (sum of the square) for response surface model of fruit $\mathrm{pH}$ during storage. Supplementary Table 4: analysis of variance (sum of the square) for response surface model of fruit acidity during storage. (Supplementary Materials)

\section{References}

[1] S. Noonari, I. N. Memon, H. Wagan, I. Mushtaque, and M. Ismail, "Performance of guava orchards production and marketing in Sindh Pakistan," Academy of Agriculture Journal, vol. 1, no. 1, 2016.

[2] C. Vishwasrao and L. Ananthanarayan, "Postharvest shelf-life extension of pink guavas (Psidium guajava L.) using HPMCbased edible surface coatings," Journal of Food Science and Technology, vol. 53, no. 4, pp. 1966-1974, 2016.

[3] L. J. Babatola and G. Oboh, "Extract of varieties of guava (Psidium guajava L.) leaf modulate angiotensin-1-converting enzyme gene expression in cyclosporine-induced hypertensive rats," Phytomedicine, vol. 1, no. 4, Article ID 100045, 2021.

[4] Y. Suwanwong and S. Boonpangrak, "Phytochemical contents, antioxidant activity, and anticancer activity of three common guava cultivars in Thailand," European Journal of Integrative Medicine, vol. 42, Article ID 101290, 2021.

[5] A. Singh, D. S. Kachway, V. S. Kuschi, G. Vikas, N. Kaushal, and A. Sigh, "Edible oil coatings prolong shelf life and improve quality of guava (Psidium guajava L.)," International Journal of Pure \& Applied Bioscience, vol. 5, no. 3, pp. 837-843, 2017.

[6] R. K. Dhall, "Advances in edible coatings for fresh fruits and vegetables: a review," Critical Reviews in Food Science and Nutrition, vol. 53, no. 5, pp. 435-450, 2013. 
[7] J.-W. Han, L. Ruiz-Garcia, J.-P. Qian, and X.-T. Yang, "Food packaging: a comprehensive review and future trends," Comprehensive Reviews in Food Science and Food Safety, vol. 17, no. 4, pp. 860-877, 2018.

[8] M. Lacroix and K. D. Vu, "Edible coating and film materials," in Innovations in Food Packaging, pp. 277-304, Academic Press, Cambridge, MA, USA, 2014.

[9] G. I. Olivas, J. E. Dávila-Aviña, N. A. Salas-Salazar, and F. J. Molina, "Use of edible coatings to preserve the quality of fruits and vegetables during storage," Stewart Postharvest Review, vol. 3, no. 6, pp. 1-10, 2008.

[10] D. Mudgil, "The interaction between insoluble and soluble fiber," in Dietary Fiber for the Prevention of Cardiovascular Disease, pp. 35-59, Academic Press, Cambridge, MA, USA, 2017.

[11] M. A. Cerqueira, A. I. Bourbon, A. C. Pinheiro et al., "Galactomannans use in the development of edible films/coatings for food applications," Trends in Food Science \& Technology, vol. 22 , no. 12 , pp. $662-671,2011$.

[12] G. Dodi, D. Hritcu, and M. I. Popa, "Carboxymethylation of guar gum: synthesis and characterization," Cellulose Chemistry and Technology, vol. 45, no. 3, p. 171, 2011.

[13] D. Mudgil, S. Barak, and B. S. Khatkar, "Guar gum: processing, properties and food applications-a review," Journal of Food Science and Technology, vol. 51, no. 3, pp. 409-418, 2014.

[14] A. H. Bahar, M. A. Ismail, A. H. Sulaiman, and S. Ali, "Characteristic evaluation of some guar (Cyamopsis tetragonoloba [L] taub) genotypes grown under rain-fed conditions at zalingei area," ARPN Journal of Science and Technology, vol. 5, no. 5, pp. 215-218, 2015.

[15] N. T. Farah, K. Ariba, Sirajuddin, and I. A. Hassan, "Analytical characterization of guar and guar gum produced in sindh, Pakistan," Food Science and Nutrition Technology, vol. 1, no. 2, pp. 2574-2701, 2016.

[16] K. Srinivasan, "Fenugreek (Trigonella foenum-graecum): a review of health beneficial physiological effects," Food Reviews International, vol. 22, no. 2, pp. 203-224, 2006.

[17] J. X. Jiang, L. W. Zhu, W. M. Zhang, and R. C. Sun, "Characterization of galactomannan gum from fenugreek (Trigonella foenum-graecum) seeds and its rheological properties," International Journal of Polymeric Materials, vol. 56, no. 12, pp. 1145-1154, 2007.

[18] N. Khorshidian, M. Yousefi Asli, M. Arab, A. Adeli Mirzaie, and A. M. Mortazavian, "Fenugreek: potential applications as a functional food and nutraceutical," Nutrition and Food Sciences Research, vol. 3, no. 1, pp. 5-16, 2016.

[19] F. Rashid, S. Hussain, and Z. Ahmed, "Extraction purification and characterization of galactomannan from fenugreek for industrial utilization," Carbohydrate Polymers, vol. 180, pp. 88-95, 2018.

[20] N. D. Işıklı and E. Karababa, "Rheological characterization of fenugreek paste (çemen)," Journal of Food Engineering, vol. 69, no. 2, pp. 185-190, 2005.

[21] M. A. Anjum, H. Akram, M. Zaidi, and S. Ali, "Effect of gum Arabic and aloe vera gel based edible coatings in combination with plant extracts on postharvest quality and storability of "Gola” guava fruits," Scientia Horticulturae, vol. 271, Article ID 109506, 2020.

[22] AACC, Approved Methods of Analysis, The American Association of Cereal Chemist, Saint Paul, MN, USA, 2000.

[23] M. Nadeem, F. Muhammad Anjum, M. A. Murtaza, and G. Mueen-ud-Din, "Development, characterization, and optimization of protein level in date bars using response surface methodology," The Scientific World Journal, vol. 2012, Article ID 518702, 10 pages, 2012.

[24] R. Malviya, P. K. Sharma, and S. K. Dubey, "Antioxidant potential and emulsifying properties of Kheri (Acacia chundra, Mimosaceae) gum polysaccharide," Marmara Pharmaceutical Journal, vol. 21, no. 3, p. 701, 2017.

[25] N. Azarakhsh, A. Osman, H. M. Ghazali, C. P. Tan, and N. Mohd Adzahan, "Optimization of alginate and gellanbased edible coating formulations for fresh-cut pineapples," International Food Research Journal, vol. 19, no. 1, 2012.

[26] P. Dutta, N. Bhowmick, S. Khalko, A. Ghosh, and S. K. Ghosh, "Postharvest treatments on storage life of guava (Psidium guajava L.) in himalayan terai region of West Bengal, India," International Journal of Current Microbiology and Applied Science, vol. 6, no. 3, pp. 1831-1842, 2017.

[27] G. Khaliq, H. T. Abbas, I. Ali, and M. Waseem, “Aloe vera gel enriched with garlic essential oil effectively controls anthracnose disease and maintains postharvest quality of banana fruit during storage," Horticulture Environment and Biotechnology, vol. 60, no. 5, 2019.

[28] M. A. Rojas-Graü, M. S. Tapia, and O. Martín-Belloso, "Using polysaccharide-based edible coatings to maintain quality of fresh-cut Fuji apples," LWT-Food Science and Technology, vol. 41, no. 1, pp. 139-147, 2008.

[29] J. Y. Lee, H. J. Park, C. Y. Lee, and W. Y. Choi, “Extending shelf-life of minimally processed apples with edible coatings and antibrowning agents," Lebensmittel-Wissenschaft undTechnologie-Food Science and Technology, vol. 36, no. 3, pp. 323-329, 2003.

[30] D. Albanese, L. Cinquanta, and M. Dimatteo, "Effects of an innovative dipping treatment on the cold storage of minimally processed Annurca apples," Food Chemistry, vol. 105, no. 3, pp. 1054-1060, 2007.

[31] G. Oms-Oliu, R. Soliva-Fortuny, and O. Martín-Belloso, "Edible coatings with antibrowning agents to maintain sensory quality and antioxidant properties of fresh-cut pears," Postharvest Biology and Technology, vol. 50, no. 1, pp. 87-94, 2008.

[32] R. Sothornvit, "Effect of edible coating on the qualities of fresh guava," Acta Horticulturae, vol. 1012, pp. 453-459, 2012.

[33] F. D. Soares, T. Pereira, M. O. Maio Marques, and A. R. Monteiro, "Volatile and non-volatile chemical composition of the white guava fruit (Psidium guajava) at different stages of maturity," Food Chemistry, vol. 100, no. 1, pp. 15-21, 2007.

[34] R. Etemadipoor, A. Ramezanian, A. Mirzaalian Dastjerdi, and M. Shamili, "The potential of gum Arabic enriched with cinnamon essential oil for improving the qualitative characteristics and storability of guava (Psidium guajava L.) fruit," Scientia Horticulturae, vol. 251, pp. 101-107, 2019. 